\title{
Bone Marrow Aspirate Immunophenotyping and Cytochemistry Were Not Performed
}

National Cancer Institute

\section{Source}

National Cancer Institute. Bone Marrow Aspirate Immunophenotyping and

Cytochemistry Were Not Performed. NCI Thesaurus. Code C160325.

An indication that immunophenotyping and cytochemistry were not performed on bone marrow aspirates during the study. 